\title{
Nebulised antipseudomonal antibiotic therapy in cystic fibrosis: a meta-analysis of benefits and risks
}

\author{
S Mukhopadhyay, M Singh, J I Cater, S Ogston, M Franklin, R E Olver
}

\begin{abstract}
Background - To establish the benefits and risks of nebulised antipseudomonal therapy in cystic fibrosis the results of relevant randomised controlled trials were combined.
\end{abstract}

Methods - The therapeutic end points compared were (a) number of pulmonary exacerbations requiring treatment with systemic antibiotics, (b) measurable alteration in respiratory tract pseudomonal load, (c) alteration in lung function on spirometric assessment, (d) development of resistance in respiratory tract Pseudomonas strains to the nebulised antipseudomonal used in each randomised controlled trial, and (e) renal and auditory impairment.

Results - Five studies were suitable for meta-analysis, eight others could not be included because of inadequate outcome description or the lack of appropriate randomisation. Meta-analysis shows benefit for nebulised antipseudomonal antibiotic therapy with no demonstrable adverse effect other than a possible increase in in vitro antibiotic resistance of Pseudomonas aeruginosa of the respiratory tract.

Conclusions - Although inferences drawn from individual randomised controlled trials concerning the benefits and risks of this form of therapy are conflicting, pooled effect size establishes benefit with nebulised antipseudomonal antibiotic therapy and emphasises its relevance to the integration of information in other areas of controversy relating to the treatment of this disease.

(Thorax 1996;51:364-368)

Keywords: meta-analysis, cystic fibrosis, systematic review, nebulised antibiotics.

Sputum colonisation with Pseudomonas species is associated with a decline in respiratory function in patients with cystic fibrosis. ${ }^{1}$ Since 1981 , 14 published studies have attempted to evaluate the effect of nebulised antipseudomonal antibiotics on respiratory status in children and adults (7-42 years of age) with Pseudomonas colonisation of the respiratory tract. ${ }^{2-15}$ Smallness of sample size, variability of study design, and the possibility of carryover effect in randomised controlled trials have confounded efficacy and safety estimates, resulting in limited areas of consensus in this field. ${ }^{61617}$ In this study we have used the statistical technique of meta-analysis to combine the results of these randomised controlled trials in order to increase statistical power to improve estimates of effect.

\section{Methods}

SEARCH STRATEGY

We followed a search strategy defined by the UK Cochrane Centre for optimal recall of randomised controlled trials. ${ }^{1819}$ The strategy is formatted for search using the SilverPlatter version 3. 10 which was adapted for the Medline database on CD-ROM from CD-Plus using Ovid search software. The main difference is that the SilverPlatter operator "near" (denoting terms within the same sentence) does not exist in the Ovid search software. We used instead the Ovid proximity operator "adjn" where two terms are within " $n$ " words of each other. We therefore replaced the SilverPlatter search statements (clin* near trial*) in titles (TI) or abstracts (AB) with the Ovid statement (clinical $\$$ adj2 trial\$).tw and the SilverPlatter statement (singl* or doubl* or trebl* or tripl*) near (blind* or mask*) in TI or in AB, with the Ovid statement ( $($ singl $\$$ or doubl $\$$ or trebl\$ or tripl $\$$ ) adj (blind $\$$ or mask $\$$ )).tw. Other statements such as (clin $\$$ adj3 trial\$).tw and (singl\$ adj2 blind\$).tw were tested but the additional references retrieved were all either irrelevant or already retrieved by other search statements. The higher the value of " $n$ " in the operator "adjn", the slower the search, therefore in the interests of speed and relevance we opted for the search statements above. A new publication type, "controlled clinical trial", introduced by the National Library of Medicine in January 1995 was added to the second stage of the search. Stage IV of the strategy searches for papers on cystic fibrosis which are not animal only studies and combines this search with stages I, II, and III in turn. The search was conducted in April 1995 and looked back as far as 1966 . The complete search strategy is given in the Appendix. Searches of Current Contents, bibliographies of textbooks, reviews, editorials, international cystic fibrosis conference proceedings and personal communications supplemented the above. Where the published information on randomised controlled trials was inadequate for meta-analysis, retrieval of unpublished data was attempted by writing letters to first authors. Only randomised controlled trials were considered for metaanalysis. Non-randomised controlled trials were used to draw up a table of descriptive analyses. 
Table 1 Clinical heterogeneity: characteristics of the randomised clinical trials listed for the meta-analysis

\begin{tabular}{|c|c|c|c|c|c|c|}
\hline $\begin{array}{l}\text { Trial } \\
\text { (code no.) }\end{array}$ & Study design & $\begin{array}{l}\text { No. of } \\
\text { patients }\end{array}$ & Antibiotics used & $\begin{array}{l}\text { Duration of } \\
\text { intervention }\end{array}$ & $\begin{array}{l}\text { Quality } \\
\text { index }\end{array}$ & $\begin{array}{l}\text { Daily cost of drugs } \\
(£ \text { sterling })\end{array}$ \\
\hline Hodson $^{2}(1)$ & Crossover & 20 & Carbenicillin + gentamicin & 6 months & $0 \cdot 8$ & \multirow{5}{*}{$\begin{array}{l}3 \cdot 60 \\
20 \cdot 23 \\
4 \cdot 20 \\
3 \cdot 60 \text { (carbenicillin } \\
+ \text { gentamicin) } \\
30 \cdot 00 \text { (ceftazidime) } \\
61 \cdot 18\end{array}$} \\
\hline Jenkins $^{5}(2)$ & Crossover & 30 & Amikacin & 3 weeks & $0 \cdot 7$ & \\
\hline Jensen $^{4}(3)$ & Parallel & 40 & Colistin & 90 days & 0.9 & \\
\hline Stead $^{3}(4)$ & Crossover (3-period) & 18 & $\begin{array}{l}\text { Carbenicillin }+ \text { gentamicin } \\
\text { or ceftazidime }\end{array}$ & 4 months & $0 \cdot 8$ & \\
\hline Ramsey $^{6}$ (5) & Crossover (3-period) & 71 & Tobramycin & 28 days & $1 \cdot 0$ & \\
\hline
\end{tabular}

The quality index ranges from 0 (lowest) to 1 (highest) (see Methods).

\section{QUALITY INDEX}

The randomised controlled trials were listed and evaluated on a quality score ${ }^{20}$ based on the following five parameters:

1. Adequate description of patient groups in terms of age, sex, sweat electrolyte criteria for diagnosis of cystic fibrosis, and documentation of respiratory tract colonisation with Pseudomonas species.

2. Adequate description of intervention in terms of name and dose of drug/placebo, duration of administration, and characterisation of delivery apparatus.

3. Adequate assessment of outcomes by clinical assessment, lung function studies, audiometry, and renal function monitoring.

4. Outcome assessment on patients completing the study and details of withdrawals or dropouts.

5. Adequate description of the effects of intervention on all measures of outcome.

Scores of 0,1 or 2 were assigned for each parameter giving a maximum attainable score of 10 . A quality index ${ }^{21}$ was determined by dividing the score attained by the maximum attainable and could thus range from 0 to 1 (table 1).

THERAPEUTIC END POINTS FOR COMPARISON The following outcome measures, defined after an initial review of the literature, were studied in order to evaluate the efficacy and safety of nebulised antibiotic treatment in cystic fibrosis: 1. The number of pulmonary exacerbations requiring treatment with systemic antibiotics. 2 . The number of patients with altered respiratory Pseudomonas load.

Table 2 Studies excluded from the meta-analysis, reason(s) for exclusion, with a descriptive analysis of conclusions in relation to the measures of outcome addressed in the meta-analysis

\begin{tabular}{|c|c|c|c|c|c|c|c|}
\hline \multirow[t]{2}{*}{ Study list } & \multirow[t]{2}{*}{ Reason for exclusion } & \multirow[t]{2}{*}{ No. of patients } & \multicolumn{5}{|c|}{ Outcome measures } \\
\hline & & & 1 & 2 & 3 & 4 & 5 \\
\hline Wall $^{10}$ & NR & 9 & + & - & - & - & - \\
\hline Kun $^{9}$ & NR & 33 & 0 & 0 & + & + & - \\
\hline Fran $z^{14}$ & NR & 28 & + & 0 & 0 & 0 & 0 \\
\hline Nathanson ${ }^{11}$ & IOD & 7 & 0 & - & - & 0 & 0 \\
\hline Wang $^{12}$ & Retrospective & 107 & 0 & ++ & 0 & ++ & 0 \\
\hline Stroobant ${ }^{15}$ & IOD & 21 & + & 0 & - & + & - \\
\hline Carswell $^{8}$ & NR & 6 & 0 & - & + & + & - \\
\hline Steinkamp ${ }^{7}$ & NR & 14 & + & - & + & + & - \\
\hline Maclusky $^{13}$ & NR, no placebo & 27 & + & - & + & ++ & - \\
\hline
\end{tabular}

$\mathrm{NR}=$ non-randomised; IOD $=$ inadequate outcome description

$0=$ outcome not addressed, $-=$ opposes, $+=$ supports, $++=$ strongly supports the conclusion that nebulised antipseudomonal therapy leads to: (1) reduction in the number of episodes in hospital to treat respiratory exacerbations with intravenous antibiotics; (2) greater numbers of subjects with measurably decreased load or eradication of Pseudomonas species in the sputum; (3) improvement in spirometric lung function; (4) greater numbers of subjects with respiratory tract Pseudomonas species resistant to the administered antipseudomonal treatment; (5) renal and auditory impairment.
3. Alteration in spirometric lung function (forced expiratory volume in one second $\left(\mathrm{FEV}_{1}\right)$ and forced vital capacity (FVC)) providing a measure of overall effect, as defined below.

4. Alteration in the number of patients with Pseudomonas species in sputum resistant to the nebulised antimicrobial treatment.

5. Increase in auditory, renal and respiratory side effects reported during the course of treatment.

\section{ESTIMATE OF COST}

The costs of alternative protocols of nebulised antipseudomonal therapy were also estimated (expenses for active drug alone as incurred by Pharmacy, Tayside Health Board, UK; prices correct for May 1994).

\section{STATISTICAL METHODS}

\section{Dichotomous outcome measures}

With the use of appropriate software ${ }^{22}$ two techniques for pooling the data were assessed. The first was the exact likelihood estimate of the common odds ratio and its associated $95 \%$ confidence intervals (CI). This method assumes a fixed treatment effect across the studies with variation in observed outcomes caused only by sampling error. It is open to criticism on the grounds that, if the accompanying exact test of heterogeneity is statistically significant, the validity of the pooled estimate can be questioned. ${ }^{23}$ An alternative method proposed by DerSimonian and Laird was therefore also used; this technique makes no assumption about the constancy of effect and incorporates a measure of interstudy variability into the pooled estimate. ${ }^{24}$

\section{Continuous outcome measures}

The overall effect of treatment (with 95\% CI) was calculated as the mean difference in normalised $\mathrm{FEV}_{1}$ and FVC within an individual trial and the weighted mean difference (WMD) across trials. ${ }^{25}$

\section{Results}

The above search strategy yielded 172 references for 1966-75, 641 for 1976-83, 832 for $1984-90$, and 740 for $1991-5$. These were then manually searched. A total of 14 clinical studies on nebulised antibiotic therapy in cystic fibrosis were identified. Table 1 lists the characteristics of the randomised controlled trials $(n=5)$ suit- 


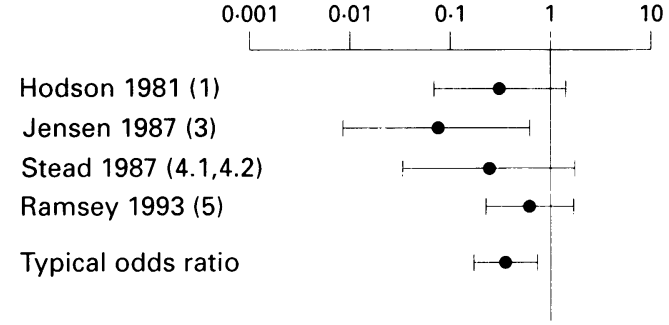

Figure 1 Individual and pooled (typical) log odds ratios with $95 \%$ confidence intervals of nebulised antipseudomonal drugs and pulmonary exacerbation requiring treatment with intravenous antibiotics. The typical odds ratio shows a statistically significant beneficial effect for nebulised antipseudomonal therapy on the number of patients developing pulmonary exacerbations who require treatment with intravenous antibiotics.

able for meta-analysis, together with the daily cost of drugs for individual antipseudomonal antibiotic protocols. Further data for study 5 were presented in a subsequent letter ${ }^{26}$ which was appended to the parent study. The quality index of the included trials ranged from 0.7 to $1 \cdot 0$. Nine trials were unsuitable for metaanalysis, the most common faults being nonrandomisation or inadequate outcome description; table 2 gives the reasons for exclusion, together with descriptive analyses of the outcome measures for these studies. Tables 3 and 4 show the results of statistical analysis of pooled outcome measures. Figures 1-3 present the individual and pooled $\log$ odds ratios in graphical form.

\section{EFFECT ON PULMONARY EXACERBATIONS}

Whilst studies 1,4 , and 5 show lack of effect, study 3 suggests beneficial effect with nebulised antipseudomonal therapy on the number of

Table 3 Typical odds ratios and pooled rate differences with 95\% confidence intervals (CI) for dichotomous outcome measures on meta-analysis of all suitable randomised clinical trials

\begin{tabular}{|c|c|c|c|}
\hline Outcome measures & $\mathrm{O} / \mathrm{T}: \mathrm{O} / \mathrm{C}$ & $\begin{array}{l}\text { Typical odds ratio } \\
(95 \% \text { CI })\end{array}$ & $\begin{array}{l}\text { Pooled rate } \\
\text { difference }(95 \% C I)\end{array}$ \\
\hline $\begin{array}{l}\text { Subjects with pulmonary } \\
\text { exacerbations treated with systemic } \\
\text { antibiotics }\end{array}$ & $16 / 85: 31 / 78$ & $\begin{array}{l}0.37 \\
(0.19 \text { to } 0.74)\end{array}$ & $\begin{array}{l}-0.22 \\
(-0.35 \text { to }-0.09)\end{array}$ \\
\hline $\begin{array}{l}\text { Subjects with decreased respiratory } \\
\text { Pseudomonas load }\end{array}$ & $12 / 81: 74 / 74$ & $\begin{array}{l}0.09 \\
(0.03 \text { to }(0.32)\end{array}$ & $\begin{array}{l}-0.22 \\
(-0.50 \text { to }-0.07)\end{array}$ \\
\hline $\begin{array}{l}\text { Subjects with Pseudomonas strains } \\
\text { resistant to nebulised antibiotic }\end{array}$ & $8 / 73: 2 / 65$ & $\begin{array}{l}3.56 \\
(0.98 \text { to } 12.88)\end{array}$ & $\begin{array}{r}0.06 \\
(-0.02 \text { to } 0.15)\end{array}$ \\
\hline
\end{tabular}

If $95 \% \mathrm{CI}$ include unity, the results are not significant. Thus, nebulised antibiotics significantly decrease respiratory Pseudomonas load, reduce the frequency of pulmonary exacerbations requiring systemic antibiotics, and do not encourage the development of resistant respiratory Pseudomonas strains (however, see text).

$\mathrm{O}=$ number positive for outcome; $\mathrm{T}=$ number treated; $\mathrm{C}=$ number of controls

Table 4 Overall effect (defined in text) of nebulised antipseudomonal therapy on respiratory function

\begin{tabular}{|c|c|c|c|c|}
\hline \multirow[t]{2}{*}{ Trial code } & \multicolumn{2}{|l|}{$\begin{array}{l}\text { Normalised FEV } \\
(\% \text { mean predicted })\end{array}$} & \multicolumn{2}{|l|}{$\begin{array}{l}\text { Normalised FVC } \\
(\% \text { mean predicted })\end{array}$} \\
\hline & Mean (SE) change & $95 \% C I$ & Mean (SE) change & $95 \% C I$ \\
\hline 3 & $6 \cdot 0(3 \cdot 6)$ & $1 \cdot 1$ to $14 \cdot 5$ & $11 \cdot 0(4 \cdot 6)$ & 1.9 to 20.1 \\
\hline $4 \cdot 1$ & $17 \cdot 0(27 \cdot 7)$ & $-37 \cdot 3$ to $71 \cdot 4$ & $9.4(16.7)$ & $-23 \cdot 4$ to $42 \cdot 2$ \\
\hline $4 \cdot 2$ & $17 \cdot 0(29 \cdot 2)$ & $-40 \cdot 3$ to $74 \cdot 3$ & $10 \cdot 2(17 \cdot 7)$ & $-24 \cdot 5$ to $44 \cdot 9$ \\
\hline & $9.7(2.5)$ & 4.8 to 14.6 & $6 \cdot 2(2 \cdot 5)$ & 1.3 to 11.0 \\
\hline Pooled effect & $8 \cdot 6(2 \cdot 0)$ & $4 \cdot 6$ to $12 \cdot 6$ & $7 \cdot 3(2 \cdot 1)$ & 3.1 to 11.5 \\
\hline
\end{tabular}

Results are presented as mean (SE) percentage change and $95 \%$ confidence intervals (CI). Nebulised antibiotics are shown to exert a significant beneficial effect on spirometric lung function. As study 4 includes two different antibiotic protocols, $4 \cdot 1$ represents the overall effect with ceftazidime and $4 \cdot 2$ with carbenicillin and gentamicin.

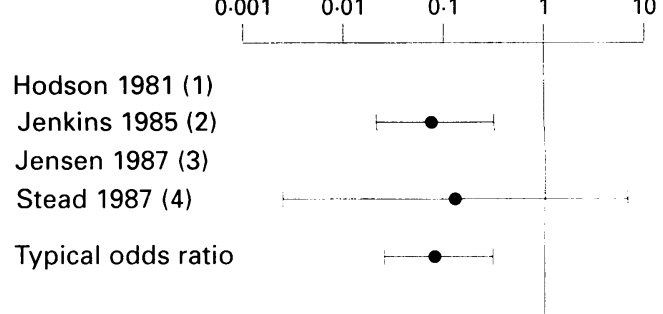

Figure 2 Individual and pooled (typical) log odds ratios with $95 \%$ confidence intervals of nebulised antipseudomonal drugs and decrease in respiratory Pseudomonas load. The typical odds ratio shows a statistically significant beneficial effect for nebulised antipseudomonal therapy on the number of subjects with a decrease in respiratory Pseudomonas load. Odds ratios could not be calculated for studies 1 and 3: there was no difference between "experiment" and "control" limbs.

patients developing pulmonary exacerbations requiring treatment with systemic antibiotics (fig 1). The pooled effect clearly demonstrates statistically significant benefit (fig 1 ; table 3 ). Study 2 does not assess this measure of outcome and hence cannot be included in the meta-analysis.

\section{EFFECT ON RESPIRATORY PSEUDOMONAL LOAD} Study 2 suggests a decrease in respiratory pseudomonal load following nebulised antipseudomonal therapy whilst studies 1,3 , and 4 show no such effect. The pooled effect is significant (fig 2 ; table 3 ). As a decrease in pseudomonal load in the sputum had not been documented on an individual patient basis, study 5 could not be included in this analysis.

\section{EFFECT ON SPIROMETRIC LUNG FUNCTION ASSESSMENT}

Spirometric lung function improved in two of the three studies (studies 3 and 5) suitable for meta-analysis; the pooled effect is significant (table 4). Study 1 does not provide standard deviations or standard errors of the mean for its data; study 2 does not evaluate spirometric lung function as a measure of outcome and hence cannot be included in the meta-analysis.

EFFECT ON PSEUDOMONAS RESISTANCE

Information on the number of subjects with tobramycin-resistant strains of Pseudomonas aeruginosa before and after active drug or placebo was not available from study 5 , thus necessitating its exclusion from this meta-analysis. Studies 1-4 qualify for meta-analytic assessment of the increase in the number of subjects with Pseudomonas species in sputum resistant to the nebulised antipseudomonal used. The odds of developing resistance were increased almost fourfold, but the results were consistent with no increase and a 12-fold increase and narrowly failed to achieve significance (fig 3; table 3).

\section{OTHER SIDE EFFECTS}

Mild chest tightness (three cases) and a bad taste in the mouth (four cases) are the only undesirable side effects described, with no 


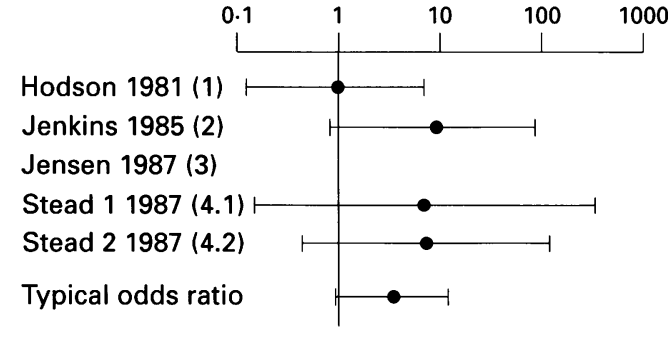

Figure 3 Individual and pooled (typical) log odds ratios with $95 \%$ confidence intervals of nebulised

antipseudomonal drugs and the development of respiratory

Pseudomonas strains resistant to the administered nebulised drug. 95\% confidence intervals for the typical odds ratio just cross the unity odds ratio line; this is consistent with the hypothesis that a type II error persists in the relationship between nebulised antipseudomomal therapy and the number of subjects with respiratory Pseudomonas strains resistant to the administered nebulised drug.

Information from study 4 allows the effects on this outcome measure of the ceftazidime (4-1) versus the carbenicillin and gentamicin (4.2) combinations in study 4 to be shown separately. An odds ratio could not be calculated for study 3 as there was no difference between "experiment" and "control" limbs.

reported effect on renal (serum creatinine and urinary creatinine clearance) and auditory (conventional audiometry) function.

\section{Discussion}

In this study we have applied the statistical technique of meta-analysis to integrate quantitatively the results of randomised controlled trials evaluating nebulised antibiotic therapy in cystic fibrosis in an attempt to answer specific questions regarding the efficacy and safety of this form of treatment, which is used widely in the treatment of respiratory deterioration associated with Pseudomonas colonisation in cystic fibrosis. ${ }^{27}$ Appropriate enquiries of cystic fibrosis physicians in the UK together with Medline searches combining "meta-analysis" or "systematic review" with "cystic fibrosis" yielded no results; thus information available to us at the time of writing indicates that this is the first systematic review on this subject. By combining the results of randomised controlled trials meeting the criteria for inclusion in the meta-analysis we have demonstrated the clear benefit of nebulised antipseudomonal antibiotics, with reductions in pulmonary exacerbations (fig 1; table 3), respiratory pseudomonal load (fig 2; table 3), and improvement in spirometric lung function (table 4). Although odds ratios and pooled rate differences for the effect of nebulised antibiotic treatment on in vitro Pseudomonas resistance included unity, and therefore failed to demonstrate significance, there remains the possibility of a type II error (fig 3; table 3). Antibiotic resistance in Pseudomonas aeruginosa is, however, often temporary and resistant strains usually grow slowly, produce small colonies, and lose the ability to produce important virulence factors such as elastase. ${ }^{28}$ Current microbiological evidence thus dissociates the development of in vitro pseudomonal resistance from adverse clinical outcome in cystic fibrosis. This is in line with the conclusions of this meta-analysis, demonstrating clinical benefit in the face of a possible increase in in vitro Pseudomonas resistance. The quality index is presented to allow comparison between randomised controlled trials in cystic fibrosis; they do not influence study inclusion. Cystic fibrosis is a well defined area of clinical research. Almost all relevant studies have been presented at regular international meetings over the period in which nebulised antibiotic therapy has evolved. Given the dearth of randomised controlled trials of nebulised antibiotics, it is very unlikely that one would go unpublished (at least as an abstract); consequently publication bias is much less likely to present as a major confounder in this field.

Even the recently reported multicentric (seven US centres) randomised controlled trial of nebulised tobramycin ${ }^{6}$ could not recruit more than 71 subjects, falling much below the figure of 500 recommended by the Cystic Fibrosis Foundation Consensus Conference report as the minimum number of subjects required for premarketing clinical trials to allow for imbalances in patient characteristics that are not amenable to adjustments in analysis. ${ }^{29}$ The last few years have witnessed the introduction of novel pharmacological interventions which may delay the inexorable decline phase of cystic fibrosis by promoting chloride efflux with uridine triphosphate, ${ }^{30}$ improving mucolysis with recombinant DNase, ${ }^{31}$ neutralising intraluminal proteolytic enzyme activity with aerosolised $\alpha_{1}$-antitrypsin $^{32}$ or recombinant secretory leukoprotease inhibitor. ${ }^{33}$ "Gene therapy" could, in the foreseeable future, evolve as a therapeutic strategy directed towards arresting or circumventing the basic defect. Adequate sample size will be of crucial importance in order to demonstrate the biological or clinical efficacy of these interventions. Nevertheless, small sample size, particularly in the face of increasing complexity of outcome measures - for example, those based on infant pulmonary function tests, serial computed tomographic scanning of the chest, or bronchoalveolar lavage for markers of inflammation - may continue to confound estimates of effect. As long as there remains in cystic fibrosis this major shortfall in the number of subjects recruitable for individual randomised controlled trials, combining results of multiple small randomised controlled trials by meta-analysis will improve estimates of effect, thus making it a useful technique for evaluating the effectiveness of therapeutic interventions. This paper demonstrates its use in establishing the beneficial effect of nebulised antipseudomonal antibiotics, identifies areas for further study, and emphasises the relevance of meta-analysis in integrating information in other controversial areas of cystic fibrosis management in order to achieve consensus.

\section{Appendix}

STAGE I

1 randomised controlled trial.pt.

2 randomised controlled trials/

3 random allocation/

4 double-blind method/

5 single-blind method/

61 or 2 or 3 or 4 or 5 
STAGE II

7 clinical trial.pt.

8 controlled clinical trial.pt.

9 exp clinical trials/

10 (clinical\$ adj2 trial\$).tw.

11 ( (singl $\$$ or doubl $\$$ or trebl $\$$ or tripl $\$$ ) adj

(blind $\$$ or mask $\$$ )).tw.

12 placebos/

13 placebo $\$$.tw.

14 random $\$$.tw.

15 research design/

167 or 8 or 9 or 10 or 11 or 12 or 13 or 14 or 15

1716 not 6

STAGE III

18 comparative study/

19 exp evaluation studies/

20 follow-up studies/

21 prospective studies/

22 (control\$ or prospectiv\$ or volunteer $\$$ ).tw.

2318 or 19 or 20 or 21 or 22

2423 not (6 or 17)

STAGE IV

25 cystic fibrosis/

26 limit 25 to human

27 limit 26 to animal

28 limit 25 to animal

2928 not 27

3025 not 29

3130 and 6

3230 and 17

3330 and 24

We wish to express our gratitude to Dr WO Tarnow-Mord Mr Gareth Parry (Child Health, Dundee) and Mr Mark Star (Cochrane Collaboration, Oxford) for advice and technical help. Nestle (Switzerland) supported MS's fellowship during th period, while Pharmax (UK) provided financial support towards literature searches and software.

1 Pitcher-Wilmott RW, Levinsky RJ, Gordon I, Turner MW, Mathew, DJ. Pseudomonas infection, allergy and cystic fibrosis. Arch Dis Child 1982;57:582-6.

2 Hodson ME, Penketh ARL, Batten JC. Aerosol carbenicillin and gentamicin treatment of Pseudomonas aeruginosa infections

3 Stead RJ, Hodson ME, Batten JC. Inhaled ceftazidime compared with gentamicin and carbenicillin in older patients with cystic fibrosis infected with
aeruginosa. Br $\mathcal{F}$ Dis Chest 1987;81:273-9.

4 Jensen T, Pedersen SS, Garne S, Heilmann C, Hoiby N, Koch C. Colistin inhalation therapy in cystic fibrosis patients with chronic Pseudomonas aeruginosa lung infection. F Antimicrob Chemother 1987;19:831-8.

5 Jenkins SG, Kelly WC, Mason WG, Peele JD, Cruse MA Coludro EO, et al. Aerosolized amikacin administration to cystic fibrosis patients chronically infected with Pseudomonas aeruginosa. Presented at the 26th Meeting of the monas aeruginosa. Presented at the 26th Meeting of the May, 1985 (abstract)

6 Ramsey BW, Dorkin HL, Eisenberg JD, Gibson RL, Harwood IR, Kravitz RM, et al. Efficacy of aerosolized to- bramycin in patients with cystic fibrosis. $N$ Engl $f \mathrm{Med}$ 1993;328: $1740-6$

7 Steinkamp G, Tummler B, Gappa M, Albus A, Potel J, Doring $\mathrm{G}$, et al. Long term tobramycin aerosol therapy in cystic fibrosis. Pediatr Pulmonol 1989;6:91-8.

8 Carswell F, Ward C, Cook DA, Speller DCE. A controlled trial of nebulized aminoglycoside and oral flucloxacillin versus placebo in the out patient management of children with cystic fibrosis. Br 7 Dis Chest 1987;81:356-60.

9 Kun P, Landau LI, Phelan PD. Nebulized gentamicin in children and adolescents with cystic fibrosis. Austr Pediat f 1984;20:43-5

10 Wall MA, Terry AB, Eisenberg J, McNamara M, Cohen R. Inhaled antibiotics in cystic fibrosis. Lancet 1983;i:1325.

11 Nathanson I, Kropp GJA, Li Philip, Neter E. Effectiveness of aerosolized gentamicin in cystic fibrosis (CF). Presented at the 26th meeting of the Cystic Fibrosis Foundation, Anaheim, California, 1619 May, 1985 (abstract).

12 Wang C, Rolden MA, Aufderheide M, Sehgal SS. The effect of tobramycin aerosol on pulmonary infection from Pseudomonas aeroginosa in patients with cystic fibrosis (CF). Presented at the 25th Annual Meeting of the Cystic Fibrosis Foundation, San Jose, California, 27-30 April, Fibrosis Found

13 Maclusky IB, Gold R, Corey M, Levison H. Long term effects of inhaled tobramycin in patients with cystic fibrosis colonized with Pseudomonas aeruginosa. Pediatr Pulmonol 1989;7:42-8.

14 Franz MN, Spohn WA, Ronald PM. Evaluation of aerosol tobramycin therapy in CF. Presented at the 26th Annual Meeting of the Cystic Fibrosis Foundation, Anaheim, California, 16-19 May, 1985 (abstract).

15 Stroobant J, Heaf DP, Tyson S, Mathews DJ. Effect of inhaled azlocillin, Mistabron and combination therapy in inhaled azlocillin, Mistabron and combination therapy in

16 MacLusky I, Levison H, Gold R, McLaughlin FJ. Inhaled antibiotics in cystic fibrosis: is there a therapeutic effect? antibiotics in cystic fibros

17 Mukhopadhyay S. When will nebulized chemotherapy come of age? Respir Med 1994;88:245-47.

18 Dickersin $\mathrm{K}$, Scherer R, Lefebvre C. Identifying relevan studies for systematic reviews. BMF 1994;309:1286-91.

19 Lefebvre C. The Cochrane Collaboration: the role of the UK Cochrane Centre in identifying the evidence. Health Libr Rev 1994;11: 235-42.

$20 \mathrm{Begg}$ CB. A measure to aid in the interpretation of published clinical trials. Stat Med 1985;4:1-9.

21 Rosenfield MR, Vertrees JE, Carr J, Cipolle RJ, Uden DL, Geibank GS, et al. Clinical efficacy of antimicrobial drugs for acute otitis media: meta-analyses of 5400 children from 33 randomized trials. I Pediatr 1994;124:355-67.

22 Chalmers TC, ed. Data analyses for clinical medicine - the quantitative approach to clinical medicine. International Uniquantitative approach
versity Press, 1988.

23 Wilson A, Henry DA. Meta-analysis: assessing the quality of published meta-analyses. Med $\mathcal{F}$ Austr 1992;156:173-8

24 DerSimonian R, Laird N. Meta-analyses in clinical trials. Control Clin Trials 1986; 7:177-88

25 Bracken MB. Statistical methods for analyses of effects of treatment in overviews of randomized trials. In: Sinclair $\mathrm{JC}$, Bracken MB, eds. Effective care of the newborn infant. Oxford: Oxford University Press.

26 Ashby BL, Stern DH. Aerosolized tobramycin in patients of cystic fibrosis. $N$ Engl F Med 1993;329:1659-60.

27 Boat TF. Cystic fibrosis. In: Behrman RE, ed. Nelson Textbook of Pediatrics. Philadelphia: WB Saunders, 1992.

28 Govan JRW, Glass S. The microbiology and therapy of cystic fibrosis lung infections. Rev Med Microbiol 1990;1: 19-28.

29 Ramsey BW, Boat TF. Outcome measures for clinical trials in cystic fibrosis. $\mathcal{F}$ Pediatr 1994;124:177-91.

30 Knowles MR, Clarke LL, Boucher RC. Activation by extracellular nucleotides of chloride secretion in the airway epithelia of patients with cystic fibrosis. $N \mathrm{Engl} \mathscr{f} \mathrm{Med}$ 1991;325:533-8

31 Shak S, Capon H, Masters SA, Baker CL. Recombinant DNase I reduces the viscosity of cystic fibrosis sputum. Proc Natl Acad Sci USA 1990;87:9188-92.

32 McElvaney NG, Hubbard RC, Birrer P, Chernick MS Caplan DB, Frank MM, et al. Aerosol $\boldsymbol{\alpha}_{1}$-antitrypsin treatment for cystic fibrosis. Lancet 1991;337:392-4.

33 McElvaney NG, Nakamura H, Birrer P, Hébert CA, Wong WL, Alphonso $\mathrm{M}$, et al. Modulation of airway inflammation in cystic fibrosis: in vivo suppression of interleukin-8 levels on the respiratory epithelial surface interleukin- 8 levels on the respiratory epithelial surface inhibitor. F Clin Invest 1992;90:1296-301. 